\title{
Individualities of Cardiorespiratory Responsiveness to Shifts in Respiratory Homeostasis and Physical Exercise in Homogeneous Groups of High Performance Athletes
}

DOI: $10.2478 / \mathrm{v} 10131-010-0001-1$

Authors' Contribution:

A - Study Design

B - Data Collection

C - Statistical Analysis

D - Data Interpretation

$F$ - Literature Search

$\mathrm{G}$ - Funds Collection
E - Manuscript Preparation

\author{
Viktor Mishchenko ${ }^{1(A, B, D, F)}$, Oksana Shynkaruk ${ }^{2}(A, D, G)$, \\ Andrzej Suchanowski ${ }^{1}(\mathrm{~A}, \mathrm{D}, \mathrm{F})$, Olena Lysenko ${ }^{2(B, D, E)}$, \\ Tomasz Tomiak $^{1(A, D, G)}$, Andrej Diachenko ${ }^{2(B, D)}$, Adam Korol ${ }^{1(B, C)}$ \\ 1Jedrzej Sniadecki Academy of Physical Education and Sport in Gdansk, \\ Poland \\ ${ }^{2}$ National University of Physical Education and Sport, Kiev, Ukraine
}

Key words: individual peculiarities, cardiorespiratory system, sensitivity to $\mathrm{CO}_{2}-\mathrm{H}^{+}$, fast kinetics, response peaks, specific work capacity.

\section{Abstract}

Background: It is known that high sports performances are based upon optimization of adaptation process. In order to achieve the above, one should provide a maximal account of individual vivid features of athlete's abilities, peculiarities of his/her physiological reactivity. The aim was to study individualities of sensitivity to shifts in respiratory homeostasis and responsiveness to high intensity physical exercises in homogeneous groups of high performance endurance athletes.

Material/Methods: Individual peculiarities of the cardiorespiratory system (CRS) physiological reactivity were evaluated in 118 high performance endurance athletes (cyclists, runners and rowers) aged 20-27 years (competing regularly in sports for $6.8 \pm 1.1$ years). The sensitivity of response to $\mathrm{CO}_{2}-\mathrm{H}^{+}$ (rebreathing), fast kinetics and the peak response of CRS to various physical loads were measured. The level of $\mathrm{VO}_{2 \max }$ and accumulated oxygen deficit were determined as well.

Results: The results indicate distinctive individual peculiarities of CRS response to the shifts of respiratory homeostasis in homogeneous groups of endurance athletes with respect to sensitivity and stability of responses to $\mathrm{CO}_{2}-\mathrm{H}^{+}$. Sensitivity to $\mathrm{CO}_{2}-\mathrm{H}^{+}$demonstrated a positive correlation with fast kinetics and peak levels in responses to physical loads and anaerobic potential realization.

Conclusions: Hyperkinetic and hypokinetic types of an individual physiological responsiveness of CRS to shifts in the respiratory homeostasis and physical exercise in homogeneous groups of high performance athletes were revealed as a premise for athletes' high specific work capacity.

Word count: 7485

Tables: 10

Received: April 2010

Figures: 3

Accepted: June 2010

References: 40

Published: September 2010

Address for correspondence:

Prof. Viktor Mishchenko

Academy of Physical Education and Sport, Department of Theory of the Olympic Sport, 80-336 Gdańsk, Poland, ul. K. Górskiego 1

Phone: +4858 554-73-66, e-mail: vmishch@awf.gda.pl 


\section{Introduction}

It is well known that high performance in sport is a single and, quite frequently, a unique event. Its achievement requires a maximal usage of individual vivid traits of an athlete's abilities, namely the biological prerequisites. It is just in this direction that the search for the ways of achieving the highest sports performances should be undertaken. Proceeding from the above, it becomes evident that the problem of individualization may be outlined as the major link in the process of top level athletes' preparation.

Under different impacts of the environment and physical loads, the adaptation has both common and individual features [1,2,3,4]. An individual predisposition to endurance activity of various intensity has been long connected almost exclusively with the morphological factors of muscles and, above all, the ratio of "slow" and "fast" muscle fibers [4,5]. The above mostly explains orientation at an individual level of maximal aerobic and anaerobic power and individualization of the training load ergo genesis [1,4,5]. These aspects of functional abilities are related to a great extent with innate features of the body although the degree of interaction between genotype and physical work capacity (and training adaptation) remains mostly unclear. An individual character of responsiveness is shown relative to the level of basal metabolism, the character of energy metabolism during physical loads, involvement of aerobic and anaerobic processes of energy supply. They are interrelated with specifics of muscle fibers, the neuromuscular system on the whole and the functional system of body oxygen supply. Individual differences are also connected with peculiarities of afferentation in the system, vegetative balance as well as personalitytypological characteristics of the central nervous system $[3,4,6,7,8]$. One may find numerous indications in scientific literature showing that according to responses to external irritants and pathogenic factors all people may be conditionally divided into persons with a hyper-, hypo-, and normoreactive type of response $[3,8,9,10,11]$.

One may assume that a regular repetition of the responses of load hypoxia compensation and acidosis in the process of several years of sports training alters a general response of the body to the action of different factors. These changes integrate both the influence of the indicated factors of sports training and individual innate physiological characteristics of responsiveness. Until now, however, there have been no sufficiently substantiated markers and criteria for determination of the indicated types of responsiveness on the basis of evaluating characteristics of the body functional system response to homeostasis shifts. It is quite difficult to single out individual peculiarities of the character of reactivity optimization during the respiratory system adaptation to a strenuous muscular activity due to a variety of the impacts of different type, direction and character of physical training. They may be also disguised by differences in the degree of adaptation and the functional state of the body. Under conditions of strenuous training in various sports events it is more difficult to single out individual peculiarities and types of responses. Meanwhile, it is of especially great practical importance for sports and endurance training, in particular. The character of the direction of long-term sports endurance training is mainly determined by specific capacity energy supplying under specific conditions of activity. It occurs, in particular, during different duration of the competitive distance. That is, we speak about individual capacities of maximal realization of energy and motor potential of an athlete within a definite period of work.

We have proceeded from the fact that the usage of various sports disciplines as the model of a definite type of human activity (physical loads) allows determining their impact upon the range and the character of differences in the cardiorespiratory system (CRS) physiological reactivity to the shifts of respiratory homeostasis. It may be characterized according to the response to hypercapnic and hypoxic shifts of respiratory homeostasis. These differences should be related to the specifics of long-term adaptation with respect to the response sensitivity change and they should reflect the specifics of human energy and functional capacity realization under conditions of physical loads. Previously obtained data demonstrating that sensitivity to hypoxia and mainly to hypercapnic $\left(\mathrm{CO}_{2}-\mathrm{H}^{+}\right)$shifts of respiratory homeostasis may reflect general physiological reactivity 
$[2,3,8,12]$ can constitute the basic provision for such an analysis. During such an analysis one may presume an availability of the correlation between sensitivity to $\mathrm{CO}_{2}$ and the speed and the level of CRS response to the action of various irritants including physical loads.

The task was set to characterize individual peculiarities of responsiveness to the shifts of respiratory homeostasis as well as the types of responsiveness to strenuous physical load in top level athletes on the basis of analysis of homogeneous groups of athletes engaged in different sports events. In the course of the above, it was necessary to determine the peculiarities of CRS response to various physical loads, the character of energy potential realization in athletes specializing in cycling, rowing and running at different distances.

\section{Material and methods}

Three groups of top level athletes of different sports specialization aged 20-27 years (homogeneous in the degree of fitness and sports qualification) participated in studies. Accordingly, three series of studies were conducted: 1) cyclists specialized in road and track races (body mass $76.8 \pm 1.4 \mathrm{~kg}, \vee^{\circ} \mathrm{O}_{2 \max } 70.3 \pm 1.4 \mathrm{ml} \cdot \mathrm{kg}^{-1} \cdot \mathrm{min}^{-1}, \mathrm{n}=46$ ), 2) track and field athletes (running disciplines, $\left.\mathrm{VO}_{2 \max } 68.7 \pm 1.7 \mathrm{ml} \cdot \mathrm{kg}^{-1} \cdot \mathrm{min}^{-1}, \mathrm{n}=48\right)$, including sprint $(\mathrm{n}=17$; body mass $77.6 \pm 1.1 \mathrm{~kg})$, long $(\mathrm{n}=16 ; 70.6 \pm 0.9 \mathrm{~kg})$ and middle distance running $(\mathrm{n}=15 ; 75.1 \pm 1,2 \mathrm{~kg}), 3)$ rowers (body mass $90.1 \pm 2.3 \mathrm{~kg}, \mathrm{VO}_{2} \max 69.8 \pm 1.3 \mathrm{ml} \cdot \mathrm{kg}^{-1} \cdot \mathrm{min}^{-1}, \mathrm{n}=24$ ). All subjects have been regularly competing in respective sports events for $6.8 \pm 1.1$ years. The data of studies of top level athletes, the majority of which were members of the national teams, were analyzed. All subjects gave informed written consent before participating in the protocol, which was in accordance with legal requirements. The subjects were free from taking drugs or medications during the course of the study. The volume and the intensity of training before and during the course of the study did not differ from usual in these groups of athletes. The mean training duration constituted $13.7 \pm 2.7$ hours/week in the period of one month before the study.

The sensitivity and stability of responses of pulmonary ventilation $\left(\mathrm{V}_{E}\right)$, heart rate $(H R)$ and respiratory sinus arrhythmia (RSA) of the cardiac rhythm to hypercapnic $\left(\mathrm{CO}_{2}-\mathrm{H}^{+}\right)$shifts of respiratory homeostasis (during rest in the supine position in the morning) were measured. Progressive hypercapnic stimulation (at the background of increased $\mathrm{O}_{2}$ content - about $50 \%$ ) was created by a rebreathing method [13]. An inclination of $\mathrm{V}_{\mathrm{E}}-\mathrm{P}_{\mathrm{A}} \mathrm{CO}_{2}$ dependence line reflecting the value of pulmonary ventilation increase by $1 \mathrm{~mm} \mathrm{Hg}$ of $\mathrm{P}_{\mathrm{A}} \mathrm{CO}_{2}$ elevation was determined. The time delay of ventilatory response to single inhalation of hypercapnic-hypoxic gas mixture $\left(7.1 \% \mathrm{CO}_{2}-\right.$ $12.2 \% \mathrm{O}_{2}$ ) was measured as well [14]. The response to incremental specific physical load performed on a cycle ergometer, a treadmill or a rowing ergometer (incremental test) and to maximal $\mathrm{O}_{2}$ consumption $\left(\mathrm{VO}_{2}\right.$ max $)$ was determined. Power was increased every 2 min until the subject reached volitional fatigue. The structure of ventilatory response was evaluated according to Hew-Euler ratio [15] which describes a dependence between pulmonary ventilation and the respiratory volume by means of two parameters: an inclination of $V_{E}-V_{T}\left(M\right.$ or $\left.\Delta V_{E} / \Delta V_{T}\right)$ line and the point of its intersection of the abscissa axis ("K" - threshold of the response of lung stretch receptors). RSA was measured in the process of enhancing a hypercapnic stimulus (rebreathing) by means of values of inter-beat interval for 60 s in the percentage of mean $R-R$ interval according to the methods suggested earlier $[3,16]$. The measurement of the maximal oxygen uptake was carried out in previous (1-2 weeks before) studies. The next testing of physical exercise on a specific ergometer has been performed using: the 30s Wingate test, unloaded cycling (100 revolutions per min, $5 \mathrm{~min}$ ), incremental (10-14 min), submaximal power at 0.7 of $\mathrm{VO}_{2} \max (5 \mathrm{~min})$ and supermaximal power at $1.1 \pm 0.07$ of $\mathrm{VO}_{2} \max (5 \mathrm{~min}$ ). Peak responses and fast kinetics (halfperiod $-T_{50}$, monoexponential, breath by breath method, transition from 25 watts on an ergometer and from $6 \mathrm{~km}$.hour ${ }^{-1}$ on a treadmill) were determined at load power of 1.1 of $\mathrm{VO}_{2}$ max. Time constant $\left(\mathrm{T}_{63}\right)$ was determined at load power of 0.7 of $\mathrm{VO}_{2} \max [17,18]$. Individual peculiarities of anaerobic capacities were estimated in rowers. For this purpose differentiated tests (maximal 
physical loads of $120 \mathrm{~s}$ and $300 \mathrm{~s}$ duration) were applied. They were aimed at estimating anaerobic reserve according to the maximal accumulated oxygen deficit - MAOD [19]. Capillary blood lactate was measured after the incremental load. Oxycon Alfa Jaeger, Cosmed b $b^{2}$, Polar Accurex Plus were used. Gas exchange data were continuously measured breath by breath using $5 \mathrm{~s}$ stationary averages. Capillary finger tip blood lactate was measured at the end of the first minute of standardized recovery ( $\mathrm{Dr}$ Lange Mini Plus). The subjects refrained from intensive exercise during the previous 24 hours (rest day) and did not perform exercises 72 hours before strenuous training workloads and maximal tests. Subjects were instructed to take a carbohydrate rich diet the days before the training sessions and exercise tests. Before the start of each test, a warm-up of 5 min was performed; it consisted of rowing ergometer load of 50-70 watts. All measurements took place under the same conditions of temperatures $\left(20-23^{\circ} \mathrm{C}\right)$ and humidity $(45-55 \%)$. Before the trials, the athletes were familiarized with the use of the ergometer and tests procedures. Statistics 5.0 PL in Excel 97 packet was used. The method of taxonomic analysis was used in order to systematize individual responses of the body to progressive hypercapnia [20].

\section{Results}

An analysis of the individuality of reactive capacities of skilled athletes' CRS requires singling out the differences related to body mass and size. The studies have shown a dependence of the sensitivity to hypercapnia on the body mass of the examined athletes. Calculations have demonstrated that an average "normal" value of $\Delta \mathrm{V} E / \Delta \mathrm{P}_{\mathrm{A}} \mathrm{CO}_{2}$ of cyclists increases by $0.035 \pm 0.003 \mathrm{~L} \cdot \mathrm{min}^{-1} \mathrm{~mm} \mathrm{Hg}^{-1}$ with the decrease in the body mass by $1 \mathrm{~kg}$ (in the range of body mass of $70-85 \mathrm{~kg}$ ). An inclination of indicated dependence line has been related to that of the dependence line of specific $\mathrm{VO}_{2}$ max on the body mass $\left(0.49 \pm 0.01 \mathrm{~mL} \cdot \mathrm{min}^{-1} \mathrm{~kg}^{-1}\right)$. The range of the above changes in the given contingent of subjects did not differ significantly $-5.0 \pm 0.09 \%$ and $4.8 \pm 0.08 \%(p>0.05)$.

A comparison of the limits of CRS responses in homogeneous groups of endurance athletes to physical loads of different intensity and duration indicates significant individual differences. Peak responses of pulmonary ventilation have been compared during $30 \mathrm{~s}$ load of maximal intensity (Wingate test), incremental load "until exhaustion" as well as during weight free pedaling (100 rev/min) on the Monarch cycle ergometer. These data of 12 athletes selected in accordance with indication of the smallest differences in $\mathrm{VO}_{2 \text { max }}$ (within the range of 64.1-67.7 $\mathrm{ml} \cdot \mathrm{kg}^{-1} \cdot \mathrm{min}^{-1}$, body mass - 70.8$75.9 \mathrm{~kg}$ ) are presented in Table 1.

Tab. 1. Individual data of $\mathrm{V}_{E}$ max, $\mathrm{HRmax}$ and $\mathrm{V}_{\mathrm{E}} / \mathrm{V}^{\circ} \mathrm{O}_{2}$ responses in a homogeneous group of skilled cyclists to weight free pedaling as well as to loads of different intensity

\begin{tabular}{|c|c|c|c|c|c|}
\hline \multirow{2}{*}{ Athletes } & \multicolumn{2}{|c|}{ Unloaded cycling } & \multirow{2}{*}{$\begin{array}{c}V_{E} \max \\
\text { incremental test, } \\
I \cdot \mathrm{min}^{-1}\end{array}$} & \multirow{2}{*}{$\begin{array}{c}V_{E} 30 \text { s test, } \\
\mathrm{I} \cdot \mathrm{min}^{-1}\left(\mathrm{I} \cdot \mathrm{min}^{-}\right. \\
\left.1 \cdot \mathrm{kg}^{-1}\right)\end{array}$} & \multirow{2}{*}{$\begin{array}{c}\mathrm{V}_{\mathrm{E}} / \mathrm{VCO}_{2} \\
30 \mathrm{~s}\end{array}$} \\
\hline & $V_{E}, \mid \cdot \min ^{-1}$ & $\mathrm{HR}$ bt $\cdot \min ^{-1}$ & & & \\
\hline$P-v$ & 39.9 & 121.5 & 114.3 & $55.1(0.76)$ & 24.1 \\
\hline $0-y$ & 46.8 & 118.5 & 109.9 & $88.2(1.23)$ & 28.1 \\
\hline P-k & 51.8 & 128.5 & 128.7 & $94.6(1.25)$ & 30.8 \\
\hline D-0 & 40.9 & 120.0 & 115.5 & $63.4(0.77)$ & 23.9 \\
\hline$A-i$ & 35.4 & 94.0 & 106.1 & $55.4(0.64)$ & 26.0 \\
\hline A-s & 26.2 & 85.0 & 128.0 & $54.9(0.71)$ & 23.2 \\
\hline$L-y$ & 35.8 & 106.5 & 138.3 & $75.6(1.38)$ & 26.8 \\
\hline D-k & 42.8 & 137.1 & 105.2 & $65.0(0.86)$ & 24.9 \\
\hline S-B & 60.3 & 141.2 & 172.1 & $137.7(2.14)$ & 39.8 \\
\hline$P-i$ & 37.8 & 114.1 & 178.0 & $103.7(1.40)$ & 29.0 \\
\hline K-n & 34.0 & 91.4 & 160.2 & $47.0(0.63)$ & 24.5 \\
\hline $\mathrm{T}-\mathrm{a}$ & 39.9 & 127.2 & 151.1 & $104.4(1.67)$ & 30.3 \\
\hline Min-max & $26.2-60.3$ & $85-141$ & $106-178$ & $\begin{array}{c}47-138 \\
(0.63-2.14)\end{array}$ & $23.2-39.8$ \\
\hline
\end{tabular}


As appears from Table 1, the peak of $\mathscr{V}_{E}$ response to $30 \mathrm{~s}$ maximal load varied in some athletes to a greater extent than the maximum response to the incremental load. The degree of individual differences in $\mathrm{V}_{\mathrm{E}} / \mathrm{NCO}_{2}$ was so pronounced, too. Despite standard conditions of weight free pedaling performance (the same frequency of pedaling) the levels of $\mathrm{V}_{E}$ and HR response of some athletes varied significantly - from 26.2 to $60.3 \mathrm{~L} \cdot \mathrm{min}^{-1}$ and from 83 to $141 \mathrm{bt} \cdot \mathrm{min}^{-1}$, respectively. It is noteworthy that these peculiarities were of a systematic character and individual levels of responses during repeated measurements varied in the range of $9-15 \%$ only. The above creates an initial basis for the usage of these indices in order to standardize the range of individual differences in the CRS response. Two types of responses are singled out: heavily expressed and weakly expressed ones. In-between these extreme types of hyper-, and hyporesponse there are intermediate (average) types of response. It is noteworthy that, as a rule, hyper-, and hyporeactivity are observed during performance of all testing physical loads. However, it is evident that the greatest differences took place during $30 \mathrm{~s}$ load. It may create prerequisites for its usage as both the test of anaerobic power and one of the indices for evaluation of an individual type of response (while taking into account the dynamics of $V_{E}$ response). During an analysis of the ratio of $\mathcal{V}_{E}$ and carbon dioxide release we have proceeded from an assumption that during the above mentioned anaerobic test pulmonary ventilation mainly depends on the volume of $\mathrm{CO}_{2}$ which is released from blood bicarbonate during buffering acidosis shifts in the body as well as the speed of this process. The greatest differences in $\mathrm{V}_{\mathrm{E}} / \mathrm{NCO}_{2}$ as well as in peaks of $\mathrm{V}_{\mathrm{E}}$ response were noted during $30 \mathrm{~s}$ load. The measurement of response differences in percentages gives almost the same expressed individual differences in indices of response during unloaded pedaling. That is why the index of $\mathrm{V}_{E} / \mathrm{NCO}_{2}$ may reflect, to a certain extent, an individual sensitivity to acidosis $\left(\mathrm{CO}_{2}-\mathrm{H}^{+}\right)$shifts in the body.

The presented data may indicate that some more common factors of the character of response formation which may be estimated according to individual levels of the respiratory response can underlie the indicated individual types of responses. In this regard, measurements of response sensitivity to hypercapnia were made. Distinct individual peculiarities of the sensitivity and stability of the respiratory response to hypercapnia were observed (Table 2). Data of $5 \%$ of cases of its greatest reduction have been presented.

Tab. 2. Expressivity of individual peculiarities of sensitivity and stability of respiratory system responses to hypercapnia (rebreathing) according to data of $5 \%$ of cyclists, $M \pm S D$

\begin{tabular}{|c|c|c|}
\hline Characteristics & $\begin{array}{l}\text { High performance } \\
\text { athletes, } n=46\end{array}$ & $\begin{array}{l}5 \% \text { of highest decrease } \\
\text { cases from the complete } \\
\text { group }\end{array}$ \\
\hline $\begin{array}{l}\text { Increase in lung ventilation by } 1 \mathrm{~mm} \mathrm{Hg} \text { increase in } \mathrm{P}_{\mathrm{A}} \mathrm{CO}_{2}\left(\Delta \mathrm{V}_{\mathrm{E}} / \Delta \mathrm{P}_{\mathrm{A}} \mathrm{CO}_{2}\right) \text {, } \\
\mathrm{I} \cdot \mathrm{min}^{-1} \cdot \mathrm{mm} \mathrm{Hg}^{-1}\end{array}$ & $1.16 \pm 0.09$ & $0.51 \pm 0.03$ \\
\hline $\begin{array}{l}\text { Increase in lung ventilation by } 1 \mathrm{~mm} \mathrm{Hg} \text { increase in } \mathrm{P}_{A} \mathrm{CO}_{2}\left(\Delta \mathrm{V}_{\mathrm{E}} / \Delta \mathrm{P}_{\mathrm{A}} \mathrm{CO}_{2}\right) \text {, } \\
\mathrm{I} \cdot \mathrm{min}^{-1} \cdot \mathrm{mm} \mathrm{Hg}^{-1} \text { related to body mass, } \mathrm{ml} \cdot \mathrm{kg}^{-1} \cdot \mathrm{min}^{-1} \cdot \mathrm{mm} \mathrm{Hg}^{-1}\end{array}$ & $14.1 \pm 1.0$ & $6.7 \pm 0.45$ \\
\hline Threshold of ventilatory response at the increase in $\mathrm{P}_{\mathrm{A}} \mathrm{CO}_{2}, \mathrm{~mm} \mathrm{Hg}$ & $37.8 \pm 1.4$ & $27.5 \pm 3.6$ \\
\hline Lung ventilation at $\mathrm{P}_{\mathrm{A}} \mathrm{CO}_{2} 50 \mathrm{~mm} \mathrm{Hg} .\left(\mathrm{V}_{\mathrm{E} 50}\right), \mathrm{I} \cdot \mathrm{min}^{-1}$ & $14.1 \pm 0.82$ & $11.4 \pm 0.94$ \\
\hline
\end{tabular}

The obtained data are indicative of the fact that some athletes are characterized by a significantly decreased sensitivity to hypercapnia. The sensitivity of ventilatory response to $\mathrm{CO}_{2}$ in $5 \%$ of athletes was 2-3 times lower as compared to the whole group of athletes of the given category. In some persons it was very low. It is noteworthy that at the standard level of $\mathrm{P}_{\mathrm{A}} \mathrm{CO}_{2}=50$ $\mathrm{mm} \mathrm{Hg}$ the general value of response in $5 \%$ of athletes showed a smaller difference because of a distinctively lower threshold of response (that is, the shift of the line of ${ }_{\mathrm{E}}{ }_{\mathrm{E}}-\mathrm{P}_{\mathrm{A}} \mathrm{CO}_{2}$ dependence to the left). As follows from the Table, cyclists with distinctively reduced sensitivity to $\mathrm{CO}_{2}$ were distinguished by a greater stability of the ventilatory response. Relatively reduced sensitivity of 
pulmonary ventilation and HR response to hypoxia was peculiar for the given group of cyclists. It should also be noted that individual differences were smaller as compared to those concerning the sensitivity to $\mathrm{CO}_{2}\left(\Delta \mathrm{V}_{\mathrm{E}} / \Delta \mathrm{P}_{\mathrm{A}} \mathrm{CO}_{2}\right)$.

An analysis of the stability of cardiac rhythm regulation mechanisms according to RSA changes in rebreathing has also revealed peculiarities related to the specialization of cyclists in distances of different duration. Increased stability of RSA in rebreathing has been also noted during the improvement of athletes' fitness in the competitive period as compared to the pre-season one. These differences of reactive features were especially apparent in the stability of the cardiac rhythm regulation under conditions of increased hypercapnia (Figure 1).

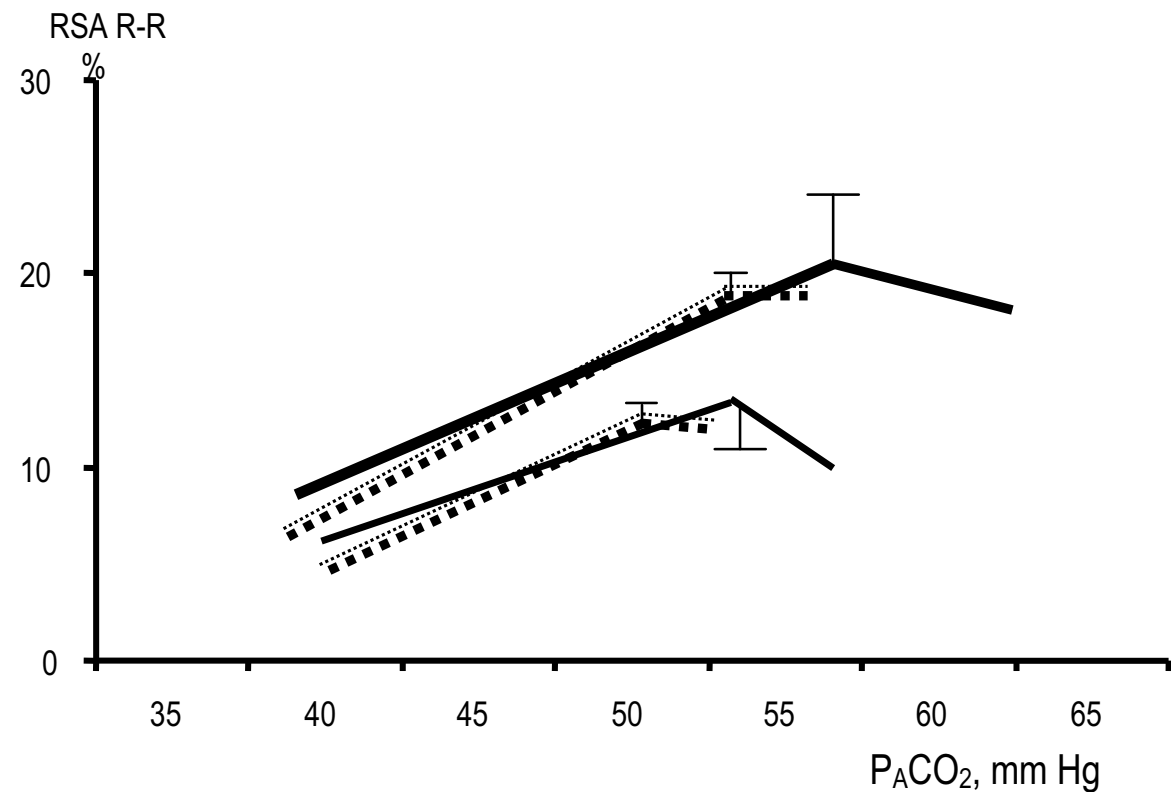

Fig. 1. Changes in the cardiac rhythm respiratory (sinus) arrhythmia (RSA R-R) during an increase in hypercapnia (rebreathing $\mathrm{CO}_{2}$ ). Upper line - road cyclists, lower line - track cyclists at the competitive stage of year training. Dotted lines - in the pre-season

Road cyclists had higher stability of maintaining the level of ventilatory response and RSA HR to an increase in $\mathrm{PCO}_{2}$. A reduction of such sensitivity (response "inhibition") under conditions of increased hypercapnic stimuli occurred in track cyclists at lower values of $\mathrm{P}_{A} \mathrm{CO}_{2}$. As is obvious from Figure 1, respiratory (sinus) arrhythmia of the cardiac rhythm (RSA R-R) increased along with elevation of $\mathrm{P}_{\mathrm{A}} \mathrm{CO}_{2}$, while the character of dependence was close to linear. This elevation continued until certain individual values of $\mathrm{P}_{\mathrm{A}} \mathrm{CO}_{2}$. Afterwards, the linear dependence was disturbed followed by a reduction in RSA. Maximum for linear dependence maintenance levels of sinus arrhythmia and $\mathrm{P}_{\mathrm{A}} \mathrm{CO}_{2}$ values were higher in road racers. RSA decrease under these conditions may indicate an exhaustion of certain aspects of capacities providing stability of efficient regulation mainly through an earlier activation of the sympathetic channel of such regulation $[16,21]$. In this case the "cost" of regulation and adaptation increases on the whole. It is interesting to note significant individual differences of RSA HR among cyclists of the homogeneous group(Table 3 ).

Tab. 3. Expressivity of individual peculiarities of RSA HR changes during progressively increased $\mathrm{CO}_{2}-\mathrm{H}^{+}-$ stimulus (rebreathing) as the reflection of sensitivity and stability of the cardiac rhythm regulation mechanism (according to data of $5 \%$ of cyclists), $\mathrm{M} \pm \mathrm{SD}$

\begin{tabular}{|l|c|c|}
\hline \multicolumn{1}{|c|}{ Characteristics } & $\begin{array}{c}\text { Complete group of high } \\
\text { performance athletes, } \\
\mathrm{n}=46\end{array}$ & $\begin{array}{c}5 \% \text { of highest decrease } \\
\text { cases from the complete } \\
\text { group }\end{array}$ \\
\hline $\begin{array}{l}\text { Maximal sinus arrhythmia of cardiac rhythm at increase of } \mathrm{P}_{\mathrm{A}} \mathrm{CO}_{2} \\
\text { in rebreathing (RSA R-R max), } \%\end{array}$ & $14.1 \pm 0.95^{*}$ & $23.1 \pm 1.15^{*}$ \\
\hline $\mathrm{P}_{\mathrm{ACO}}$ at the onset of $\triangle \mathrm{V}_{\mathrm{E}} / \triangle \mathrm{P}_{\mathrm{A}} \mathrm{CO}_{2}$ decrease, $\mathrm{mm} \mathrm{Hg}$ & $63.2 \pm 0.84^{*}$ & $68.3 \pm 0.71^{*}$ \\
\hline $\mathrm{P}_{\mathrm{ACO}}$ at the onset of $\mathrm{RSA} \mathrm{R}-\mathrm{R}$ max decrease $\left(\mathrm{PACO}_{2} \downarrow \mathrm{RSA}\right), \mathrm{mm} \mathrm{Hg}$ & $51.3 \pm 0.68^{*}$ & $54.8 \pm 0.82^{*}$ \\
\hline
\end{tabular}

* - significant differences at $p<0.05$ 
As is clear from the Table, $5 \%$ of athletes from the homogeneous group of cyclists were characterized by higher RSA as well as a greater stability of the cardiac rhythm regulation during an increase in $\mathrm{CO}_{2}-\mathrm{H}^{+}$- stimulus.

Not only the sensitivity of the ventilatory response to respiratory homeostasis shifts but its temporal indices (time of response delay) as well were connected with fast kinetics of the ventilatory response during a physical load. Data of time of ventilatory response delay to single inhalation of hypercapnic-hypoxic gas mixture $\left(7.1 \% \mathrm{CO}_{2}-12.2 \% \mathrm{O}_{2}\right)$ and the time constant of lung ventilation during a submaximal ergometric exercise $\left(0.7 \mathrm{VO}_{2}\right.$ max $)$ of 8 best track cyclists $(4$ km pursuit) are presented in Fig. 2.

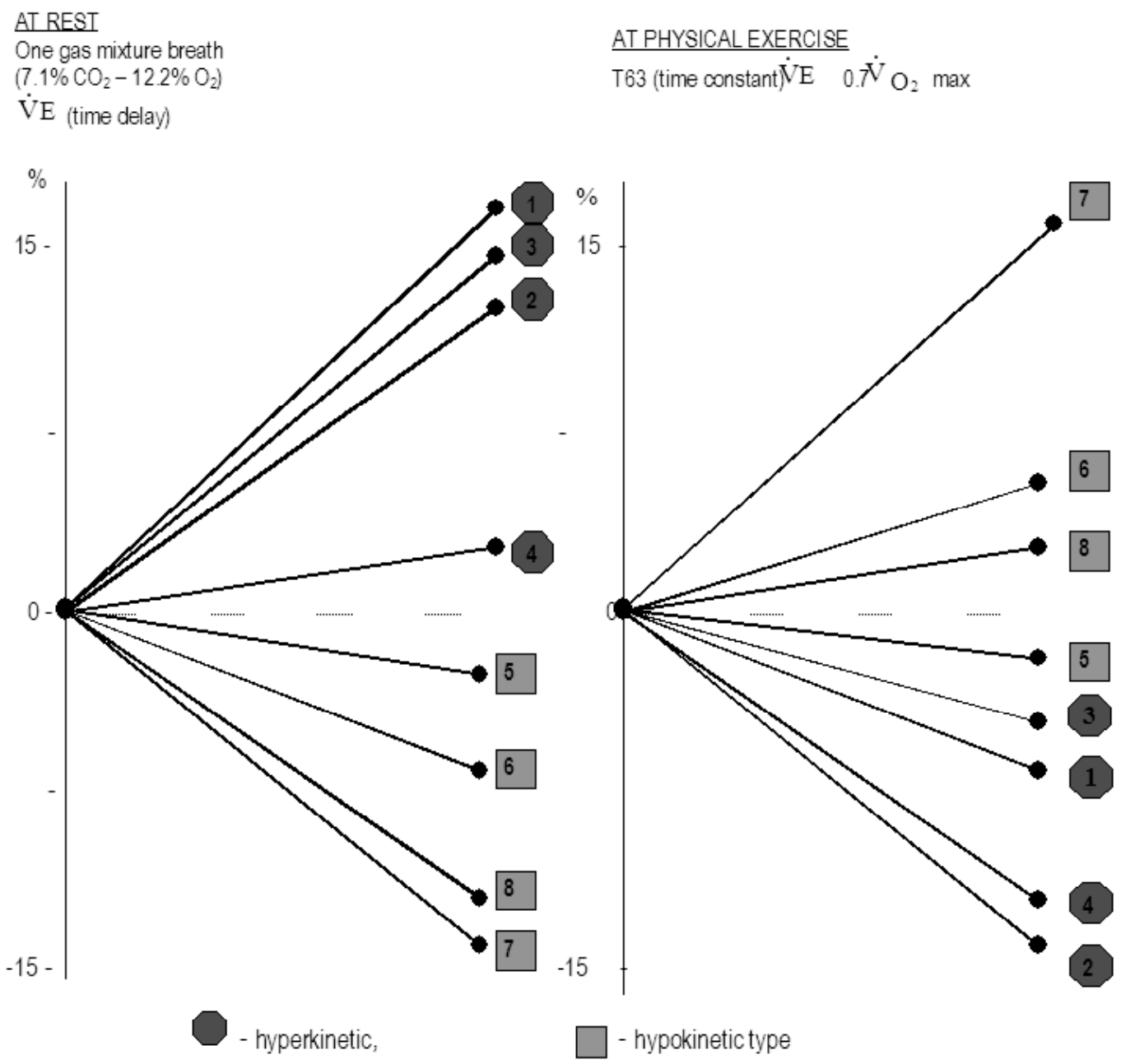

Fig. 2. Individual data of high performance cyclists' (pursuit) lung ventilation fast kinetics response difference (\%) to a hypercapnic-hypoxic stimulus (time delay) at rest and to submaximal ergometric exercise $\left(0.7 \mathrm{VO}_{2}\right.$ max, time constant), as "zero"- mean data for all athletes

It appears from Figure 2 that according to "time constant" under the standard loads the athletes with expressed hyper- and hypokinetic characteristics of response are clearly distinguished. It should be noted that a similar character of differences remains in the majority of athletes according to the time of response delay to single inhalation of hypercapnic-hypoxic gas mixture $(r=0.86)$.

Taking the indices of respiratory response of homogeneous group of 46 skilled cyclists to physical loads as the basis, three types of CRS responses have been singled out (Table 4). Normative zones of hyperkinetic and hypokinetic responses presented in the Table are outlined as 
the percentile zones of $10 \%$ of extreme meanings. Indices with the highest interindividual variability were used.

Tab. 4. Normative zones of CRS response for singling out the types of reactivity in skilled cyclists (on the data of homogeneous group of cyclists)

\begin{tabular}{|c|c|c|c|c|}
\hline \multirow{2}{*}{ Reactivity type } & \multicolumn{2}{|c|}{ Unloaded cycling } & \multicolumn{2}{c|}{30 max } \\
\cline { 2 - 5 } & $V_{E}, I \cdot \mathrm{min}^{-1}$ & $\mathrm{HR}, \mathrm{bt} \cdot \mathrm{min}^{-1}$ & $\begin{array}{c}\mathrm{V}_{\mathrm{E}, \mathrm{I}} \cdot \mathrm{min}^{-1} \\
\left(I \cdot \mathrm{min}^{-1} \cdot \mathrm{kg}^{-1}\right)\end{array}$ & $\mathrm{V}_{\mathrm{E}} / \mathrm{VCO}_{2}$ \\
\hline Hyperkinetic & $49.3-62.0$ & $136-141$ & $128-140(1.9-2.17)$ & $35.6-40.4$ \\
\hline Hypokinetic & $18.1-26.2$ & $81-98$ & $46.1-63.4(0.6-1.0)$ & $26.6-31.4$ \\
\hline Intermediate & $28.5-40.6$ & $106-131$ & $71.0-105.2(1.2-1.6)$ & $22.8-25.0$ \\
\hline
\end{tabular}

An analysis demonstrates that the most reliable definition of hyperkinetic or hypokinetic reactivity type is possible in case of due account of all presented indices. However, taking into consideration the fact that in $75 \%$ of cases three of four presented data of one athlete correspond to one of the presented reactivity types, one may use fewer indices for this purpose.

The studied response to hypercapnic $\left(\mathrm{CO}_{2}-\mathrm{H}^{+}\right)$stimulation of runners has shown significant individual differences among them. An application of taxonomy algorithm [20] by means of combining persons with the most similar responses to the $\mathrm{CO}_{2}-\mathrm{H}^{+}$-stimulus into one taxon (group) has permitted us to single out three types of responses to the $\mathrm{CO}_{2}-\mathrm{H}^{+}$-stimulus. A classification of individual responses to a hypoxic stimulus in the given group of athletes has failed to provide clear results to single out groups of athletes according to the type of response. Therefore, a subsequent analysis of response to physical loads has been carried out according to the criteria of response to the $\mathrm{CO}_{2}-\mathrm{H}^{+}$- stimulus.

An analysis of dependence between a $\mathrm{P}_{\mathrm{A}} \mathrm{CO}_{2}$ increase and pulmonary ventilation enhancement (response sensitivity) in athletes with different types of responses has demonstrated that in athletes of the group of the most expressed response (type 1 of response) the "enhancement coefficient" of response $\left(\Delta \mathrm{V}_{\mathrm{E}} / \Delta \mathrm{P}_{\mathrm{A}} \mathrm{CO}_{2}\right)$ constituted $2.27 \pm 0.16 \mathrm{~L} \cdot \mathrm{min}^{-1} \mathrm{~mm} \mathrm{Hg}^{-1}$. In athletes of type III of response a decreased value in $\Delta \mathrm{V}_{\mathrm{E}}^{\circ} / \Delta \mathrm{P}_{\mathrm{A}} \mathrm{CO}_{2}\left(1.09 \pm 0.14 \mathrm{~L} \cdot \mathrm{min}^{-1} \mathrm{~mm} \mathrm{Hg}^{-1}\right)$ has been observed as compared to that of athletes from other groups. An average level of this index $\left(1.59 \pm 0.11 \mathrm{~L} \cdot \mathrm{min}^{-1} \mathrm{~mm} \mathrm{Hg}^{-1}, \mathrm{p}<0.05\right)$ has been noted in athletes of type II of response. The differences between groups were significant $(p<0.05)$. It is noteworthy that the level of $\mathrm{P}_{\mathrm{A}} \mathrm{CO}_{2}$ during which $\mathrm{O}_{2}$ rebreathing has stopped due to hardly surmountable subjective feelings was significantly lower in athletes with the first type of responsiveness $(53.31 \pm 1.04 \mathrm{~mm} \mathrm{Hg})$ as compared to those with the second $(59.08 \pm 3.21 \mathrm{~mm} \mathrm{Hg})$ and the third one $(58.71 \pm 2.04 \mathrm{~mm} \mathrm{Hg})$ $(p<0.05)$.

Significant differences between groups of runners with different types of responsiveness have been observed not only in the "enhancement coefficient" of ventilation response $\Delta V_{E} / \Delta P_{A} C O_{2}$ ) but its threshold (point of "apnea") as well. For instance, in athletes with the first type of responsiveness a significantly lower threshold value of $\mathrm{P}_{\mathrm{A}} \mathrm{CO}_{2}-31.3 \pm 0.9 \mathrm{~mm} \mathrm{Hg}$ has been observed as compared to that noted in athletes with the second $(35.4 \pm 0.9 \mathrm{~mm} \mathrm{Hg})$ and the third $(36.6 \pm 0.8 \mathrm{~mm} \mathrm{Hg})$ type of responsiveness $(p<0.05)$. Lower values of $\Delta \mathrm{V}_{E} / \Delta \mathrm{P}_{\mathrm{A}} \mathrm{CO}_{2}$ have been accompanied with a higher threshold of the ventilatory response to $\mathrm{CO}_{2}$. The above has been especially clear during a comparison of athletes with type I and III of responsiveness. Such data may presumably indicate an expansion of the zone of chemoreceptor insensitivity to $\mathrm{CO}_{2}-\mathrm{H}^{+}-$ stimulus in athletes with type III of responsiveness. Higher ventilatory response in athletes with the first (sprint) type of responsiveness has also been characterized by a more expressed response of 
$\mathrm{HR}$ to $1 \mathrm{~mm} \mathrm{Hg}$ increase of $\mathrm{P}_{A} \mathrm{CO}_{2}$. Besides, the highest values of $\mathrm{V}_{E}$ and $\mathrm{HR}$ have been noted in these athletes under standard levels of hypercapnic stimulation $\left(\mathrm{P}_{\mathrm{A}} \mathrm{CO}_{2}=50 \mathrm{~mm} \mathrm{Hg}\right)-$ Table 5 .

Tab. 5. Characteristics of the heart rate $(H R)$ and pulmonary ventilation $\left(V_{E}\right)$ responses to $\mathrm{CO}_{2}-\mathrm{H}^{+}$-stimulus in runners with different types of responsiveness, $M \pm S D$

\begin{tabular}{|l|c|c|c|c|}
\hline \multirow{2}{*}{ Characteristics } & \multicolumn{3}{c|}{ Groups of athletes related to different types } & \multirow{2}{*}{$\begin{array}{c}\text { P(t-test) } \\
<0.05\end{array}$} \\
\cline { 2 - 4 } & High (type 1) & Middle (type 2) & Low (type 3) & \\
\hline $\mathrm{VE}_{\mathrm{E}}$ at $\mathrm{P}_{\mathrm{A}} \mathrm{CO}_{2} 50 \mathrm{~mm} \mathrm{Hg}\left(\mathrm{V}_{\mathrm{E} 50)}\right), \mathrm{ml} \cdot \mathrm{kg}^{-1} \cdot \mathrm{min}^{-1}$ & $535.0 \pm 42.9$ & $294.8 \pm 39.2$ & $207.8 \pm 28.2$ & $1-2,3 ; 2-3$ \\
\hline $\mathrm{HR}$ at $\mathrm{P}_{\mathrm{A}} \mathrm{CO}_{2} 50 \mathrm{~mm} \mathrm{Hg}\left(\mathrm{HR}_{50}\right), \mathrm{bttmin}^{-1}$ & $74.3 \pm 2.8$ & $70.8 \pm 3.2$ & $67.0 \pm 2.0$ & $1-2,3 ; 2-3$ \\
\hline $\begin{array}{l}\text { Increment } \mathrm{HR} \text { by } 1 \mathrm{~mm} \mathrm{Hg} \text { increase in } \mathrm{P}_{\mathrm{A}} \mathrm{CO}_{2} \\
\left(\Delta \mathrm{HR} / \Delta \mathrm{P}_{\mathrm{A}} \mathrm{CO}_{2}\right), \text { bt.min-1-1 } \mathrm{mm} \mathrm{Hg} \cdot{ }^{-1}\end{array}$ & $1.29 \pm 0.13$ & $0.96 \pm 0.09$ & $0.64 \pm 0.14$ & $1-3$ \\
\hline
\end{tabular}

As seen in the Table analyzed characteristics in athletes of type I of responsiveness were significantly higher as compared to those in athletes of type III.

Athletes with different types of responsiveness have also differed in peculiarities of the breathing regime. These peculiarities were connected with individual differences in sensitivity of Herring-Breyer reflex. For instance, in runners with different types of responsiveness differences in the structure of ventilatory response - the ratio of tidal volume and the respiratory rate increase have been observed. They were largely due to mechanisms of respiration self-regulation. The character of differences was close to that presented above for the response to $\mathrm{CO}_{2}$ (Table 6).

Tab. 6. Dependence between pulmonary ventilation and tidal volume as a reflection of lung stretch receptors under conditions of hypercapnic stimulation of runners with different types of responsiveness, $M \pm S D$

\begin{tabular}{|l|c|c|c|c|}
\hline \multirow{2}{*}{ Characteristics } & \multicolumn{3}{|c|}{ Groups of athletes related to different types } & \multirow{2}{*}{$\begin{array}{c}\text { of (t-test) } \\
<0.05\end{array}$} \\
\cline { 2 - 4 } & High (type 1) & Middle (type 2) & Low (type 3) & \\
\hline $\begin{array}{l}\text { Increase in lung ventilation by 1 ml increase in tidal } \\
\text { volume }\left(\Delta \mathrm{V}_{\mathrm{E}} / \Delta \mathrm{V}_{\mathrm{T}}\right), \mathrm{I} \cdot \mathrm{min}^{-1}\end{array}$ & $20.9 \pm 1.2$ & $16.2 \pm 1.9$ & $11.9 \pm 1.8$ & $1-2,3 ; 2-3$ \\
\hline Lung ventilation at tidal volume 2I $\left(\mathrm{V}_{\mathrm{E} 2 \mathrm{I}}\right), \mathrm{I} \cdot \mathrm{min}^{-1}$ & $36.9 \pm 1.7$ & $24.0 \pm 2.1$ & $17.5 \pm 3.0$ & $1-2,3 ; 2-3$ \\
\hline
\end{tabular}

As seen in Table 6 in athletes with type I of responsiveness the level of $V_{E}$ at $V_{T}=2$ liters $\left(V_{E 21}\right)$ was significantly higher $\left(507 \pm 37 \mathrm{~mL} \cdot \mathrm{kg}^{-1} \cdot \mathrm{min}^{-1}\right)$ than that in athletes with type II and III of responsiveness $(p<0.05)$. Higher accretion of pulmonary ventilation per unit of the tidal volume increase $\left(\Delta \mathrm{V}_{\mathrm{E}} / \Delta \mathrm{V}_{\mathrm{T}}\right)$ has also been observed in athletes with type I of responsiveness as compared to those with type III. The above was indicative of increased sensitivity of lung stretch receptors.

In order to estimate interdependent functioning of CRS elements in runners with different types of responsiveness, changes of cardiac rhythm respiratory (sinus) arrhythmia and its stability in the course of increased hypercapnia have been subjected to analysis (Table 7). 
V. Mishchenko, O. Shynkaruk, A. Suchanowski et al., Cardiorespiratory Responsiveness to Shifts in Respiratory Homeostasis and Physical Exercise in High Performance Athletes

Tab. 7. Values of cardiac rhythm respiratory arrhythmia and its stability under conditions of increased hypercapnic stimulation (rebreathing) in skilled runners with different types of responsiveness, $M \pm S D$

\begin{tabular}{|c|c|c|c|c|}
\hline \multirow{2}{*}{ Characteristics } & \multicolumn{3}{|c|}{$\begin{array}{l}\text { Groups of athletes related to different types } \\
\text { of responsiveness }\end{array}$} & \multirow{2}{*}{$\begin{array}{l}P(t-t e s t) \\
<0.05\end{array}$} \\
\hline & High (type 1) & Middle (type 2) & Low (type 3) & \\
\hline $\begin{array}{l}\text { Maximal sinus arrhythmia of cardiac rhythm at the } \\
\text { increase in } \mathrm{P}_{A} \mathrm{CO}_{2} \text { in rebreathing (RSA R-R max), \% }\end{array}$ & $14.13 \pm 2.24$ & $19.51 \pm 2.24$ & $22.08 \pm 2.96$ & $1-2,3$ \\
\hline $\begin{array}{l}\text { Sinus arrhythmia of cardiac rhythm at } \mathrm{P}_{\mathrm{A}} \mathrm{CO}_{2} 50 \mathrm{~mm} \\
\mathrm{Hg}\left(\mathrm{RSA}_{50}\right), \%\end{array}$ & $12.30 \pm 1.01$ & $14.29 \pm 0.82$ & $18.73 \pm 1.04$ & $1-2,3 ; 2-3$ \\
\hline $\begin{array}{l}\mathrm{P}_{A} \mathrm{CO}_{2} \text { at the onset of RSA R-R max decrease } \\
\left(\mathrm{P}_{\mathrm{A}} \mathrm{CO}_{2} \downarrow \mathrm{RSA}\right), \mathrm{mm} \mathrm{Hg}\end{array}$ & $49.91 \pm 0.98$ & $53.04 \pm 1.08$ & $56.18 \pm 1.18$ & $1-2,3 ; 2-3$ \\
\hline
\end{tabular}

As follows from Table $7, \mathrm{P}_{\mathrm{A}} \mathrm{CO}_{2}$ decrease in cardiac rhythm respiratory arrhythmia was significantly higher in athletes with type III of responsiveness as compared to that observed in athletes with types I and II. The highest stability of cardiac rhythm regulation under conditions of hypercapnia was observed in athletes with type III of responsiveness, whereas the lowest one - in those with type I. Significantly lower values of respiratory arrhythmia maximum $\left(R S A_{\max }\right)$ and respiratory arrhythmia of the cardiac rhythm were noted in the latter at $\mathrm{P}_{\mathrm{A}} \mathrm{CO}_{2} 50 \mathrm{~mm} \mathrm{Hg}\left(\mathrm{RSA}_{50}\right)$. It may be indicative of an earlier increase in sympathetic influences in cardiac rhythm regulation during growth of acidosis changes in the body internal environment.

The obtained data demonstrate that an increase in the duration of the major competitive distance leads to a reduction in response sensitivity to hypercapnia. It is confirmed by an analysis of the correlation between the length of distance the runners are specialized at and the indices of sensitivity to hypercapnia (according to $\Delta \mathrm{V}_{\mathrm{E}} / \Delta \mathrm{P}_{\mathrm{A}} C \mathrm{O}_{2}$ it constitutes $\mathrm{r}=-0.87$; according to $\Delta \mathrm{HR} / \Delta \mathrm{P}_{\mathrm{A}} \mathrm{CO}_{2}-\mathrm{r}=-0.82$; and according to $\left.\mathrm{V}_{\mathrm{E} 50}-\mathrm{r}=-0.64 ; \mathrm{p}<0.05\right)$.

The subsequent analysis has shown that the group of runners with a high level of responsiveness (type I) included $93.7 \%$ of athletes specialized in sprint, the group of athletes with an average level of physiological reactivity (type II) included $89.4 \%$ of middle distance runners, and the group of runners with a reduced level of responsiveness (type III) consisted of $94.8 \%$ of long distance runners. It should be noted that peculiarities of athletes' CRS responsiveness to the shifts of respiratory homeostasis had a certain impact on the limits of respiratory response (Table 8).

Tab. 8. Characteristics of the limits of CRS response in groups of runners with different types of responsiveness to respiratory homeostasis shifts during an incremental test, $M \pm S D$

\begin{tabular}{|c|c|c|c|c|}
\hline \multirow{2}{*}{ Characteristics } & \multicolumn{3}{|c|}{$\begin{array}{c}\text { Groups of athletes related to different types } \\
\text { of responsiveness }\end{array}$} & \multirow{2}{*}{$\begin{array}{l}P(t \text {-test }) \\
<0.05\end{array}$} \\
\hline & $\begin{array}{l}\text { High } \\
\text { (type 1) }\end{array}$ & $\begin{array}{l}\text { Middle } \\
\text { (type 2) }\end{array}$ & $\begin{array}{l}\text { Low } \\
\text { (type 3) }\end{array}$ & \\
\hline$V_{E \max }$ at the end of the load, $\mathrm{ml} \cdot \mathrm{min}^{-1} \cdot \mathrm{kg}^{-1}$ & $1574 \pm 124$ & $1872 \pm 119$ & $2222 \pm 78$ & $1-2,3 ; 2-3$ \\
\hline $\mathrm{HR}$ max, beat $\cdot \mathrm{min}^{-1}$ & $191.0 \pm 4.5$ & $186.5 \pm 4.5$ & $184.2 \pm 5.6$ & - \\
\hline $\mathrm{V}_{\mathrm{E}} / \mathrm{VO}_{2}$ & $29.9 \pm 1.8$ & $30.5 \pm 2.4$ & $29.8 \pm 0.70$ & \\
\hline $\mathrm{V}_{\mathrm{E}} / \mathrm{NCO}_{2}$ & $26.9 \pm 3.1$ & $32.7 \pm 1.3$ & $36.6 \pm 2.2$ & $1-2,3 ; 2-3$ \\
\hline Peak of the respiratory ratio $\left(\mathrm{VCO}_{2} / \mathrm{VO}_{2}\right)$ in first min of recovery & $1.45 \pm 0.12$ & $1.22 \pm 0.11$ & $1.04 \pm 0.08$ & $1-2,3 ; 2-3$ \\
\hline Blood La in the first min of recovery, $\mathrm{mmol} \cdot \mathrm{F}^{-1}$ & $11.79 \pm 0.75$ & $8.96 \pm 0.86$ & $7.64 \pm 0.96$ & $1-2,3$ \\
\hline
\end{tabular}

As is obvious from Table 8, under the load of incremental power performed until "exhaustion" reduced sensitivity of CRS response to $\mathrm{CO}_{2}-\mathrm{H}^{+}$in the groups of athletes with different types of responsiveness has been accompanied with regularly higher "peak" levels of pulmonary ventilation 
per $\mathrm{kg}$ of the body mass. It should be stressed in this regard that the achievement of $\mathrm{VO}_{2 \text { max }}$ by athletes with different types of responsiveness has not been accompanied with significant differences in $\mathrm{V}_{\mathrm{E}} / \mathrm{VO}_{2}$ release. At the same time the ratio of $\mathrm{V}_{\mathrm{E}} / \mathrm{NCO}_{2}$ was the highest in the group of athletes with a reduced type of responsiveness. It should be noted, however, that athletes with different types of responsiveness have also differed in the speed of achieving individual limits of responses. This fact has necessitated an analysis of individual peculiarities of fast kinetics of CRS responses.

Fast kinetics of $\mathrm{VO}_{2}$ and $\mathrm{V}_{\mathrm{E}}$ at the submaximal load was higher in sprinters as compared to long distance runners. For instance, $\mathrm{T}_{50} \mathrm{VO}_{2}$ constituted $25.5 \pm 1.8$ and $28.9 \pm 2.1 \mathrm{~s}$, whereas $\mathrm{T}_{50} \mathrm{~V}_{\mathrm{E}}-$ $38.6 \pm 2.9$ and $45.9 \pm 3.3 \mathrm{~s}$, respectively; $p<0.05$ ). Just the opposite was observed at the power of $\mathrm{VO}_{2}$ max - fast kinetics was the lowest in the group of sprinters and the highest in long and middle distance runners. For instance, $\mathrm{T}_{50} \mathrm{VO}_{2}$ was $29.8 \pm 3.0 \mathrm{~s}$ in sprinters and $24.4 \pm 2.9 \mathrm{~s}$ in long distance runners $(p<0.05)$. The above value was the lowest in middle distance runners $(22.8 \pm 2.5 \mathrm{~s})$. Studies of fast kinetics of responses in a homogeneous group of rowers specialized only at $2000 \mathrm{~m}$ competitive distance (duration about 5-6 min) demonstrated significant individual differences as well (Table 9).

Tab. 9. The CRS fast kinetics measured by time constant $\left(\mathrm{T}_{63}\right)$ at exercise power of $0.7 \mathrm{VO}_{2} \max (5 \mathrm{~min})$ and by half time $\left(T_{50}\right)$ at power $1,1 \mathrm{VO}_{2}$ max in high performance rowers $(n=12)$

\begin{tabular}{|c|c|c|c|c|}
\hline \multirow{2}{*}{ Values } & \multicolumn{2}{|c|}{ Time constant $\left(\mathrm{T}_{63}\right)$} & \multicolumn{2}{c|}{$\begin{array}{c}\text { Half time }\left(\mathrm{T}_{50}\right) \text { power } \\
1.1 \mathrm{VO}_{2} \text { max }\end{array}$} \\
\cline { 2 - 5 } & Mean (SD) & $\begin{array}{c}\text { Individual } \\
\text { min-max }\end{array}$ & Mean (SD) & $\begin{array}{c}\text { Individual } \\
\text { min-max }\end{array}$ \\
\hline $\mathrm{VO}_{2}, \mathrm{~S}$ & $28.2(1.8)$ & $23.2-36.1$ & $23.4(1.7)$ & $17.3-34.5$ \\
\hline $\mathrm{V}^{\circ} \mathrm{O}_{2, \mathrm{~S}}$ & $47.3(3.9)$ & $34.0-63.1$ & $32.3(2.8)$ & $24.9-48.0$ \\
\hline $\mathrm{HR}, \mathrm{s}$ & $19.5(1.2)$ & $14.3-26.0$ & $16.0(1.3)$ & $13.5-24.1$ \\
\hline $\mathrm{V}_{\mathrm{E}, \mathrm{S}}$ & $49.8(3.9)$ & $35.2-68.0$ & $34.2(2.9)$ & $26.2-48.6$ \\
\hline
\end{tabular}

Table 9 shows significant individual variations in fast kinetics of oxygen consumption, heart rate and $\mathrm{CO}_{2}$ release and pulmonary ventilation, in particular. They were observed both at the submaximal load (with respect to $T_{63}$ ) and the supermaximal power of load (with respect to $T_{50}$ ). The above may indicate that an individual character of responsiveness (with respect to both the amount and the speed of response) is determined by both the impact of long-term sports specialization, natural selection for the given specialization and innate features of CRS physiological reactivity.

Analysis has demonstrated that higher $\mathrm{VCO}_{2}$ at similar values of the load power was noted in persons with relatively higher levels of sensitivity to $\mathrm{CO}_{2}-\mathrm{H}^{+}$. As seen in the Table, higher values of blood lactate concentration and higher peak gas exchange ratio were peculiar for these persons after an incremental load test as well. The above provided grounds to suggest an availability of individual peculiarities for realization of anaerobic reserve of the body of athletes with different types of responsiveness. In order to test this suggestion, we have analyzed individual peculiarities of the degree of anaerobic capacity realization in a homogeneous group of athletes of the same specialization (rowers) which differed in the type of responsiveness - either hypokinetic or hyperkinetic one. It was earlier shown that, as a rule, the higher the realization of anaerobic reserve (with respect to MAOD) is, the more the maximal testing load approaches (in duration) the specific for an athlete competitive load [22,23,24]. Therefore, two maximal testing loads (100 s and $300 \mathrm{~s}$ ) were used for such a comparison. Six athletes with the greatest differences in physiological reactivity were selected according to the above presented criteria. Athletes of hyperkinetic (1-6) and hypokinetic (7-12) types were paired according to the criteria of the section method. Levels of athletes' ${ }^{\circ} \mathrm{O}_{2}$ max were also compared. These data are presented in Table 10. 
Tab. 10. A comparison of MAOD (during different duration of the maximal load) and $\mathrm{VO}_{2}$ max in an incremental test in athletes with relatively increased (hyperkinetic type -1) and reduced (hypokinetic type - 2) responsiveness

\begin{tabular}{|c|c|c|c|c|c|c|}
\hline \multirow{2}{*}{$\begin{array}{c}\text { Pairs (couples) } \\
\text { of athletes }\end{array}$} & \multicolumn{2}{|c|}{$\begin{array}{c}\text { MAOD 120 s, } \\
\mathrm{ml} \cdot \mathrm{kg}^{-1}\end{array}$} & \multicolumn{2}{c|}{$\begin{array}{c}\text { MAOD } 300 \mathrm{~s}, \\
\mathrm{ml} \cdot \mathrm{kg}^{-1}\end{array}$} & \multicolumn{2}{c|}{$\begin{array}{c}\mathrm{VO}_{2} \mathrm{max} \\
\mathrm{ml} \cdot \mathrm{kg}^{-1} \mathrm{~min}^{-1}\end{array}$} \\
\cline { 2 - 7 } & 1 & 2 & 1 & 2 & 1 & 2 \\
\hline $1-7$ & 59 & 48 & 52 & 56 & 71.3 & 69.1 \\
$2-8$ & 63 & 60 & 54 & 67 & 67.4 & 68.3 \\
$3-9$ & 51 & 49 & 49 & 53 & 72.3 & 70.1 \\
$4-10$ & 62 & 54 & 53 & 59 & 65.2 & 67.3 \\
$5-11$ & 52 & 41 & 43 & 48 & 69.8 & 67.3 \\
\hline $6-12$ & 49 & 43 & 43 & 50 & 72.6 & 70.8 \\
\hline Mean & $56.0^{*}$ & 49.1 & 49.0 & $55.5^{*}$ & 69.7 & 68.7 \\
\hline
\end{tabular}

* - significant difference $(p<0.01)$

As seen in Table 10, athletes of the hyperkinetic type had higher anaerobic capacities according to the results of a shorter maximal load (120 s), whereas rowers of the hypokinetic type - according to those of a longer testing load (300 s). Significant differences in the level of aerobic power (according to $\mathrm{VO}_{2}$ max) were not observed. There was only a tendency to slightly higher values in rowers of the hyperkinetic type of responsiveness. The presented data indicate that athletes with relatively higher expressivity of hyperkinetic traits of responsiveness better realized their anaerobic reserve at a shorter duration of maximal load than those with the hypokinetic type of responsiveness. These findings provide additional grounds for individualization of anaerobic tests and training means.

Monitoring of aerobic power characteristics and training loads of the above mentioned hyperkinetic and hypokinetic rowers in pre-season and in season has shown some peculiarities in increasing of CRS exercise peak values response in the test of $\mathrm{VO}_{2}$ max (Fig.3).

As seen from Figure 3 in persons with relatively higher CRS reactivity (hyperkinetic type) at similar values and intensity of training loads, individual peaks of $\mathrm{VO}_{2}$ max, exercise lung ventilation and cardiac output were reached earlier (at the end of the preparatory stage). In rowers with relatively lower CRS reactivity (hypokinetic type), peaks of $\mathrm{VO}_{2}$ max, exercise lung ventilation and cardiac output were reached later (in the competitive stage). Increasing exercise lung ventilation and cardiac output peaks from pre-season to season was significantly higher in hyperkinetic rowers $(p<0.05)$. These results provide additional grounds for individualization of the training load guideline and optimizing of long term adaptation. 

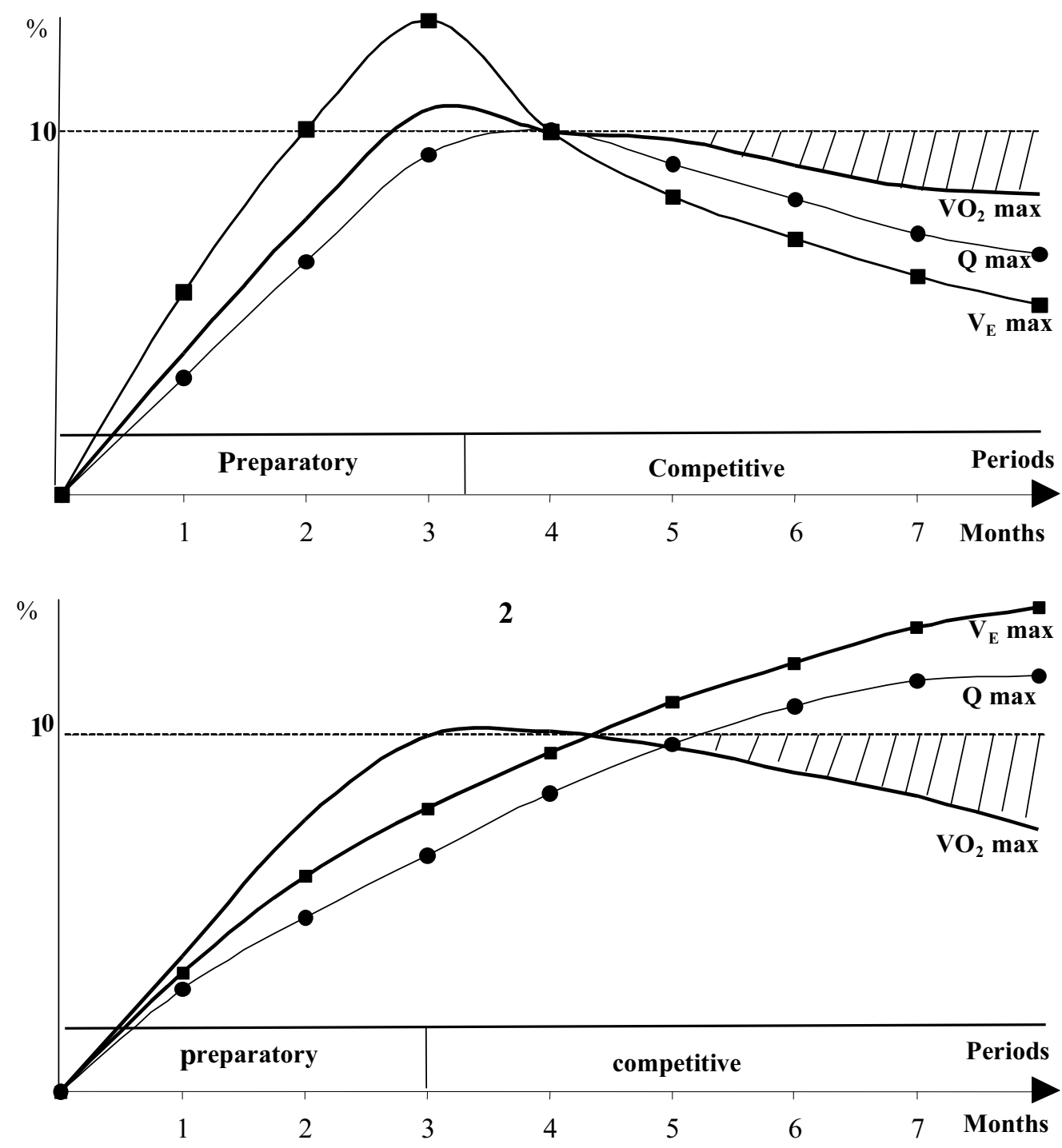

Fig.3. The changes (in \%) in $\mathrm{VO}_{2}$ max, peaks of exercise lung ventilation ( $\mathbb{V}_{\mathrm{E}}$ max) and cardiac output (Q max) in yearly preparation of high performance rowers hyperkinetic (upper part of Figure - 1) and hypokinetic (at the bottom - 2) type

\section{Discussion}

It is well known that the account of mental individuality (personality) of an athlete, the level of his physical fitness, morphofunctional peculiarities, age, the degree of development of special fitness components, above all, underlie the basis of sports training individualization $[25,26]$. One may assume that the individuality of responses to training programs and individual property of athlete's ability to get trained are determined, first of all, by an innate predisposition for reacting to factors of internal and external environment.

An individual approach to endurance sports is mainly directed nowadays at the correction of aerobic and anaerobic power of athletes $[1,3,4,5,25,26,27,28]$. However, individual differences in energy cost of work, for instance during running (about 20\%) level changes in the process of 
special work capacity training even in homogeneous groups of skilled athletes [8,17]. There are other factors of this type, for instance, such as the initial kinetics of oxygen intake and other responses of CRS. They exert a significant influence upon the involvement of anaerobic processes of work energy supply [22,23,24,29]. In fact, the only indices which are used for the current individual management of training loads are the monitoring of work capacity and lactate threshold indices. For this purpose a great number of various approaches and indices for estimation of anaerobic metabolism threshold are applied in ratio with maximal oxygen intake $[1,4,5]$ as well as other methods meeting the given conception - MLSS, La-minimum, etc. [3,25,28,30]. Managing impacts are usually aimed at the achievement of the level of endurance components typical of the best athletes of the given discipline - "model of best athletes" [25,31]. Such an approach is subjected to well-grounded criticism because it fails to account for athlete's individuality [26,32]. The application of this approach is explained by an insufficient examination of the essence and the role of individual endurance factors in this or that sports discipline. Meanwhile it is known that many elite endurance athletes have very high (almost similar) levels of aerobic and anaerobic power and indices of anaerobic threshold. One may suppose that the highest individual differences in special work capacity of these athletes would be observed in factors determining possibilities of realization of the available energy potential $[3,7,8,22,24]$. In the given study of endurance athletes we have proceeded from an important role for the above sensitivity and stability of responses to the shifts of respiratory homeostasis and other factors of the physical load. To put it in other words, an individual physiological reactivity of CRS should be of great importance for an analysis of individual differences in realization of the energy potential of athletes in the process of sports training.

It is known that acidosis is the most significant sensitivity factor which may determine individual differences of $\mathrm{CRS}$ responses during a strenuous physical load. Therefore, $\mathrm{CO}_{2}-\mathrm{H}^{+}$represents the key chemical stimulus of the respiratory response [33,34,35]. Neural influences of working extremities and brain represent another factor which determines physiological reactivity of CRS. We have assumed that on the basis of a definite complex of physical load tests as well as application of an analysis of the cardiac rhythm and determination of sensitivity to $\mathrm{CO}_{2}-\mathrm{H}^{+}$one may single out the types of responsiveness. Individual peculiarities of sensitivity to hypercapnia, as it was earlier indicated, take place not only in the level but in the range of changes within long periods of time as well $[2,3,36,37]$. Significantly increased sensitivity to $\mathrm{CO}_{2}$ in some athletes (relative to mean data) of the given study is rather noteworthy. For instance, in some athletes the value of $\Delta \mathrm{V}_{\mathrm{E}} / \Delta \mathrm{P}_{\mathrm{A}} \mathrm{CO}_{2}$ was in the range of $2.1-3.5 \mathrm{~L} \cdot \mathrm{min}^{-1} \mathrm{~mm} \mathrm{Hg}{ }^{-1}$. The number of such athletes constituted about $8 \%$, which approximately corresponded to the amount of persons with such a peculiarity of ventilatory response to hypercapnia among non-trained people $[8,36]$. Athletes with increased sensitivity to $\mathrm{CO}_{2}$ (like other endurance trained persons) were characterized by reduced sensitivity to a hypoxic irritant of respiration and its decreased interaction with a hypercapnic irritant [8]. At the same time, they were also characterized by lesser stability of the respiratory response during incremental hypercapnic stimulation. Besides, in athletes with increased sensitivity to $\mathrm{CO}_{2}$ a certain "compensation" of increased sensitivity to $\mathrm{CO}_{2}$ at the expense of an elevated threshold of response to $\mathrm{CO}_{2}$ was observed. Obtained data indicate a possibility of using several specific characteristics of respiratory arrhythmia during hypercapnia for evaluation of the dynamics of an individual training status of an athlete with account of its specifics. It is known that enhancement of parasympathetic activity measured by respiratory (sinus) arrhythmia, to a certain extent, reflects the level of endurance training status $[3,16,21,30]$. The elevation of respiratory arrhythmia correlates with an increase in the depth of breathing, the systolic volume at a relative decrease in resting RF and HR and during submaximal loads. However, utilization of indices of parasympathetic activity enhancement for the training status estimation is complicated due to the susceptibility of these values to the influence of several uncontrolled factors. It is, above all, the impact of psychoemotional tension and some other non-specific factors which tend to increase the 
tone of sympathetic division of the autonomic nervous system. We have supposed that increased hypercapnic stimulus ("drive") would allow reducing the role of non-specific factors and creating conditions for a more distinct manifestation of parasympathetic activity changes induced by sports training. On this basis one may increase the possibilities of estimating the training status of endurance trained athletes with due account of sports discipline specifics. Application of this index requires additional research because of its practical significance. It should be stressed that individual dynamics of sensitivity to hypercapnia (according to $\Delta \mathrm{V}_{\mathrm{E}} / \Delta \mathrm{P}_{\mathrm{A}} \mathrm{CO}_{2}$ ) in the process of sports training showed a significant positive correlation with the dynamics of the inclination of $\Delta \mathrm{V}_{E} / \Delta \mathrm{V}_{\mathrm{T}}$ the dependence line which reflected sensitivity of lung stretch receptors $(r=0.69$, $p<0.05)$. This may indicate higher total reactivity of vegetative centers of the given athletes. Therefore, according to indices of CRS reactivity to hypercapnic stimulus, both "hypo-" and "hypercapnic" variants of response have been observed which corresponds to the notions about hypo- and hyperergic individual peculiarities of body reactivity $[2,10]$, availability of "hypo"- and "hyperreactors" among people [5,11,12], individual types of people - "sprinters" and "stayers" $[4,9,26]$. However, specific criteria for their determination have not been proposed until now. An elaboration regarding sports training where a person is functioning on the verge of exceeding the limits of his capacities may be of tremendous practical significance.

The obtained data have also demonstrated a higher levels of anaerobic glycolytic processes of energy supplying, similarly to the power of load in athletes with higher level of reactivity to $\mathrm{CO}_{2}-\mathrm{H}^{+}$. This is most peculiar for sprinters (100 m running). A correlation analysis has revealed a positive relationship between the level of CRS response sensitivity to $\mathrm{CO}_{2}$ and the level of anaerobic glycolytic process activity in energy supplying under conditions of the load. $\mathrm{VCO}_{2}$ increase and its correlation with $\mathrm{VO}_{2}\left(\mathrm{VCO}_{2} / \mathrm{VO}_{2}\right)$ have been directly correlated with the level of sensitivity of ventilatory $\left(r=0.81\right.$ for $\left.\Delta V_{E} / \triangle P_{A} C O_{2}\right)$ and circulatory $\left(r=0.78\right.$ for $\left.\Delta H R / \Delta P_{A} C O_{2}\right)$ responses to respiratory homeostasis shifts $(p<0.05)$.

It is also necessary to take into account the fact that the degree of relative prevalence of $\mathrm{CO}_{2}$ release over $\mathrm{O}_{2}$ uptake contributes to the development of hypocapnia of physical exercises. It is known that it may reduce the efficiency of oxygen transport functions in the body and may represent one of the factors limiting physical work capacity $[35,38,39]$. That is why the stability to hypocapnia is also an important element of CRS adaptation to high intensity physical loads $[8,40]$. The higher the intensity of the processes of metabolic acidosis respiratory compensation is, the greater its significance. An interdependent analysis of gas exchange ratio and blood lactate concentration provides an indirect judgment of the above. An analysis of gas exchange ratio and blood lactate concentration indicates the availability of the highest prerequisites for expressivity of hypocapnia in athletes with a relatively higher level of CRS reactivity. Taking into consideration the specificity of special work capacity, one may assert that the greatest significance of stability to hypocapnia is during middle-distance running. Data indicating higher anaerobic power in athletes of the hyperkinetic type of CRS responsiveness according to the results of a shorter maximal load (120 s), whereas in those of the hypokinetic type - according to the results of longer testing load (300 s) provide every reason to differentiate tests for estimation of anaerobic reserve (according to MAOD) depending on the individual type of athlete.

Therefore, specific manifestations of adaptation to a certain type of training physical loads have been characterized by a directed modification of the respiratory system reactivity (sensitivity and stability) to respiratory homeostasis shifts. This modification may play a role of a power formation mechanism for respiratory compensation of metabolic acidosis which permits to apply the indices of sensitivity and stability of responses to $\mathrm{CO}_{2}-\mathrm{H}^{+}$for individual estimation and prediction of the effects of strenuous training and character of long-term adaptation of athletes with different types of reactivity. 


\section{Conclusion}

The obtained data may provide an initial basis for a differentiation of standards of physiological reactivity of athletes' CRS. These findings proved that the peculiarities of physical reactivity of CRS of athletes specialized in running at different distances are the result of both long-term adaptation to sports loads of various direction and long-term natural selection of athletes. High athletic performances in any sports discipline were only achieved by athletes with respective hereditary prerequisites. It has been demonstrated that the sensitivity to $\mathrm{CO}_{2}-\mathrm{H}^{+}$-stimulus adequately reflects prerequisites for specialization in sprint or distance running. The obtained data will assist in solving the tasks of skilled athlete preparation individualization. At the same time they indicate an insufficient level of current knowledge explaning individual features of regulatory mechanism of CRS adaptation during endurance training as well as a greater number of possible ways of adaptation than it is considered nowadays.

\section{References}

1. Keul J, Konig D, Huonker M, Halle M, Wohlfahrt B, Berg A. Adaptation to training and performance in elite athletes. The American Alliance for Health, Physical Education, Recreation and Dance. 1996;67(3):29-36.

2. Agadzanian A, Polunin IN, Stepanov VK, Poliakov VN. Chelovek v uslovijah hipokapnii i hiperkapnii [Man under conditions of hypocapnia and hypercapnia]. Moscow: Medicine; 2001 [in Russian].

3. Mishchenko V, Monogarov V. Physiology of Athlete. Barcelona: Paidotribo; 1995.

4. Viru A. Adaptation in sport training. London: Times Mirror International Publishers; 1995.

5. Wilmore JH., Costill DL. Physiology of Sport and Exercise. Champaign: Human Kinetics; 1994.

6. Di Prampero PE. Factors limiting maximal performance in human. Eur J Appl Physio/2003;90,3-4:420-429.

7. Suchanowski A. Indywidualizacja w treningu wytrzymałości specjalnej sportowców wysokiej klasy [Individualization of special endurance development in high performance athletes] Gdańsk: AWFiS; 2002 [in Polish].

8. Mishchenko V, Lusenko L, Vinogradov V. Reaktivnuje svojstva kardiorespiratornoj sistemu [Cardiorespiratory reactivity changes related to adaptation to physical training in sports]. Kiev: Nauchnyj Mir [Scientific Word]; 2007 [in Russian].

9. Kaznacheev V. Sovremennuje aspektu adaptacii [Modern aspects of adaptation]. Novosibirsk: Nauka [Science]; 1990 [in Russian].

10. Ado A. Voprosu obschej nozoologii [Issues of general nosology]. Moskva: Medicine; 1985 [in Russian].

11. Sirotinin N. Evolocija resistentnosci i reaktivnosti organizma [Evolution of resistance and sensitivity of the body]. Moskva: Medicine; 1981 [in Russian].

12. Berezovsky $\vee$, Serebrovska T. Respiratory system individual reactivity and its evaluation. J Physiol 1988;34(6):3-7.

13. Rebuck AS. Measurement of ventilatory response to $\mathrm{CO}_{2}$ by rebreathing. Chest 1976;70 (Suppl.):118-120.

14. Dejours P. Control of respiration in muscular exercise. Handbook of Physiology: Respiration. Washington: MSN; 1964.

15. Euler CV, Herrero F, Wexler T. Control mechanisms determining rate and depth of respiratory movements. Respirat Physiol 1970;10:93-108.

16. Bayevski RM. Analysis of cardiac rhythm variability in medicine of cosmos. JPhysiol Men 2002;28(2):70-82.

17. Burnley M, Jones A. Oxygen uptake kinetics as a determinant of sport performance. Eur J Sport Sci 2007;7(2):63-79.

18. Ward S, Lamarra N, Whipp B. The control components of oxygen uptake kinetics during high intensity exercise in human. Nice: Eur Coll Sport Sci 1996:268-270.

19. Medbo J. Is the maximal accumulated oxygen deficit on adequate measure of the anaerobic capacity? Can J Appl Physiol 1996;21:370-383.

20. Bushow JV, Protasov KT. Taxonomical analysis of body individual response upon testing hypoxic impacts. J Physiol Men 1991;17:123-128.

21. Perini R. Heart rate variability and autonomic activity at rest and during exercise in various physiological conditions. Eur J Appl Phys 2003;90(3-4):317-325.

22. Diachenko AJ. Sovershenstvovanie specialnoj vunoslivosti kvalificirovannyh sportsmenov [Enhancement of special endurance in qualified athletes]. Kiev: HPF Slavutich-Delfin; 2004 [in Russian].

23. Tomiak T. Teoretyczno-metodyczne podstawy doskonalenia wytrzymałości specjalnej wioślarzy klasy mistrzowskiej [Theoretical and methodolical bases of special endurance increase in high performance 
rowers]. Gdansk; AWFiS; 2008 [in Polish].

24. Faina M, Billat V, Squadrone R, De Angelis M, Koralsztein JP, Dal Monte A. Anaerobic contribution to the time to exhaustion at the minimal exercise intensity at which maximal oxygen uptake occurs in elite cyclists, kayakists and swimmers. EurJ Appl Physiol.1997;76:13-20.

25. Dick FW. Sports training principles. London: A\&C Black Ltd; 2007.

26. Platonov $\mathrm{V}$. Sistema podgotovki sportsmenov $\mathrm{v}$ olimpijskom sporte [System of athletes' preparation in the Olympic sport]. Kiev: Olympic Literature; 2004 [in Russian].

27. Dickhuth H, Yin L, Niess A. Ventilatory, lactate-derived and catecholamine thresholds during incremental treadmill running: relationship and reproducibility. Int J Sports Med 1999;20:122-127.

28. Gore CJ, editor. Physiological tests for elite athletes. Australian Sports Commission; 2000.

29. Kilding E, Challis NV, Winter EM, Fysh M. Characterization, asymmetry and reproducibility of on- and off-transient pulmonary oxygen uptake kinetics in endurance-trained runners. Eur J Appl Physiol: 2005;93(5-6):588-597.

30. Winter EM, Jones AM, Davison R, Bromley PD, Mercer TH, editors. Sport and exercise physiology testing. The British Association of Sport and Exercise Sciences Guide, vol. 1. London and New York: Routledge Taylor\&Fransis Group; 2007.

31. Sozanski H, editor. Bases of sports training theory. Warszawa: COS; 1999.

32. Czerwiński J, Jastrzębski Z. Proces szkolenia w zespołowych grach sportowych [Preparation process in sport games]. Gdańsk: AWFiS; 2006 [in Polish].

33. Mines AH. Respiratory physiology.New York: Raven Press; 1993.

34. Berger KI, Ayappa I, Sorkin IB, Norman RG, Rapoport DM, Goldring RM. Post event ventilation as a function of $\mathrm{CO}_{2}$ load during respiratory events. Appl Physiol 2002;93(3):917-924.

35. Bussotti M, Magri D, Previtali E, Agostoni P. End-tidal pressure of $\mathrm{CO}_{2}$ and exercise performance in healthy subjects. Eur J Appl Physiol 2008;103:727-732.

36. Kelley MA, Lauff M, Millman K. Ventilatory response to hypercapnia before and after athletic training. Respirat Physiol 1984;55:393-400.

37. Ohyabu Y, Usami A, Ohyabu I, Ishida Y, Miyagawa C, Arai T, Honda Y. Ventilatory and heart rate chemosensitivity in track-and-field athletes. Eur J Appl Physiol 1990;59:460-464.

38. Schneider $\mathrm{D}$, Berwick $\mathrm{J}$. $\mathrm{V}_{\mathrm{E}}$ and $\mathrm{VCO}_{2}$ remain tightly coupled during incremental cycling performed after a bout of high-intensity exercise. Eur J Appl Physiol 1998;77:72-76.

39. Chicharro JL, Hoyos J, Lucía A. Effects of endurance training on the isocapnic buffering and hypocapnic hyperventilation phases in professional-cyclists. Br J Sport Med 2000;34:450-455.

40. Bentley DJ, Vleck VE, Millet GP. The isocapnic buffering phase and mechanical efficiency: relationship to cycle time trial performance of short and long duration. Can J Appl Physiol 2005;30(1):46-60. 